\title{
Correction: The Effect of Different AR Nanostructures on the Optical Performance of Organic-Inorganic Halide Perovskite Semiconductor Solar Cell
}

\author{
Ali Hajjiah ${ }^{1}$ (D) Hussein Badran ${ }^{1} \cdot$ Nader Shehata $^{2,3,4,5} \cdot$ May Omran · Ishac Kandas H,3,5 $^{2}$ \\ Published online: 7 March 2022 \\ (c) The Author(s), under exclusive licence to Springer Science+Business Media, LLC, part of Springer Nature 2022
}

\section{Correction to: Plasmonics https://doi.org/10.1007/s11468-021-01547-x}

The original version of this article unfortunately contained a mistake. There should be 3 affiliations of the author Ishac Kandas. The original article has been corrected.

Publisher's Note Springer Nature remains neutral with regard to jurisdictional claims in published maps and institutional affiliations.

The original article can be found online at https://doi.org/10.1007/ s11468-021-01547-x.

Ali Hajjiah

ali.hajjiah@ku.edu.kw

Hussein Badran

badran.hussein23@gmail.com

Nader Shehata

nader.shehata@alexu.edu.eg; n.shehata@kcst.edu.kw

May Omran

mai.omran352@gmail.com

Ishac Kandas

ishac.kandas@alexu.edu.eg

Department of Electrical Engineering, College

of Engineering and Petroleum, Kuwait University,

13133 Kuwait City, Kuwait
2 Department of Engineering Mathematics and Physics, Faculty of Engineering, Alexandria University, Alexandria 21544, Egypt

3 Department of Physics, Kuwait College of Science and Technology, Safat 13133, Kuwait City, Kuwait

4 Faculty of Science, USTAR Bio-Innovation Center, Utah State University, Logan, UT 84341, USA

5 Center of Smart Materials, Nanotechnology, and Photonics (CSMPN), Smart Critical Infrastructure (SmartCI) Research Center, Alexandria University, Alexandria 21544, Egypt 